\title{
Letter
}

\section{Therapeutic hypothermia after cardiac arrest - the implementation of the ILCOR guidelines in clinical routine is possible!}

\author{
Christian Storm, Joerg C Schefold, Lutz Nibbe, Frank Martens, Anne Krueger, Michael Oppert, \\ Achim Joerres and Dietrich Hasper
}

\begin{abstract}
Charité Universitätsmedizin Berlin, Campus Virchow-Klinikum, Department of Nephrology and Medical Intensive Care Medicine, Augustenburger Platz 1, 13353 Berlin, Germany
\end{abstract}

Corresponding author: D Hasper, Dietrich.Hasper@charite.de

Published: 2 November 2006

This article is online at http://ccforum.com/content/10/6/425

(c) 2006 BioMed Central Ltd

See related letter by Sander et al., http://ccforum.com/content/10/2/407
Critical Care 2006, 10:425 (doi:10.1186/cc5061)

In none of the patients were serious adverse events potentially related to therapeutic hypothermia, such as clinically relevant bleeding episodes or arrhythmias, observed. In 12 out of 28 patients (42.9\%) treated with therapeutic hypothermia a favourable neurologic outcome was reached (Cerebral Performance Category 1 or 2).

However, recent studies have shown that only a minority of resuscitated patients are treated with therapeutic hypothermia in both American and European intensive care units [2-4]. A letter recently published in Critical Care reported the use of therapeutic hypothermia in Germany in only 38\% of departments treating patients after cardiac arrest [5].

To improve adherence to the ILCOR guidelines we developed a written standard operating procedure (SOP) for patients after cardiac arrest admitted to our 38-bed medical intensive care unit.

Starting in December 2005 the SOP was to be applied to all comatose patients after cardiac arrest, irrespective of the initial rhythm. Since then the SOP has been applied in 28 out of 34 eligible patients. For four patients the physician in charge did not consider therapeutic hypothermia despite clear indication. In two other patients hypothermia was considered to be contraindicated because of extensive coronary vasospasm or massive pulmonary bleeding of a bronchial carcinoma, respectively. In all the remaining 28 patients surface cooling with technical devices (CritiCool from MTRE, Yavne Israel, and ArcticSun from Medivance, Louisville, KY, USA) was used to induce and maintain hypothermia for 24 hours. The target temperature of $33^{\circ} \mathrm{C}$ was reached in $6.0 \pm 3.2$ hours (mean \pm SD).
Although our limited experience does not yet permit a valid statistical evaluation of the impact of therapeutic hypothermia on the neurological outcome of the patients, initial results are encouraging. We are currently trying to shorten the time to target temperature, which we feel was still too long in some patients. However, the simple availability of a written SOP has already led to the application of therapeutic hypothermia in the vast majority of our patients after cardiac arrest. All physicians caring for such patients should be encouraged to establish their own protocol for therapeutic hypothermia at their institutions, to facilitate the widespread application of this evidence-based treatment.

\section{Competing interests}

The authors declare that they have no competing interests.

\section{References}

1. Nolan JP, Morley PT, Vanden Hoek TL, Hickey RW, Kloeck WG, Billi J, Bottiger BW, Morley PT, Nolan JP, Okada K, et al.: Therapeutic hypothermia after cardiac arrest: an advisory statement by the advanced life support task force of the International Liaison Committee on Resuscitation. Circulation 2003, 108:118-121.

2. Abella BS, Rhee JW, Huang KN, Vanden Hoek TL, Becker LB: Induced hypothermia is underused after resuscitation from cardiac arrest: a current practice survey. Resuscitation 2005, 64:181-186. 
3. Merchant RM, Soar J, Skrifvars MB, Silfvast T, Edelson DP, Ahmad F, Huang KN, Khan M, Vanden Hoek TL, Becker LB, et al.: Therapeutic hypothermia utilization among physicians after resuscitation from cardiac arrest. Crit Care Med 2006, 34:1935-1940.

4. Laver SR, Padkin A, Atalla A, Nolan JP: Therapeutic hypothermia after cardiac arrest: a survey of practice in intensive care units in the United Kingdom. Anaesthesia 2006, 61:873-877.

5. Sander M, von Heymann C, Spies C: Implementing the International Liaison Committee on Resuscitation guidelines on hypothermia after cardiac arrest. The German experience: still a long way to go? Crit Care 2006, 10:407. 